\title{
micromachines
}

ISSN 2072-666X

www.mdpi.com/journal/micromachines

Article

\section{Design and Analysis of a High Force, Low Voltage and High Flow Rate Electro-Thermal Micropump}

\section{Ghader Yosefi ${ }^{1, \dagger}$, Sattar Mirzakuchaki ${ }^{2, \dagger, *}$, Farshid Raissi ${ }^{3, \dagger}$ and Saeid Afrang ${ }^{4, \dagger}$}

1 Department of Electrical Electronics Engineering, Science and Research Branch, Islamic Azad University, Tehran 14778-93855, Iran; E-Mail: gh.yosefi@srbiau.ac.ir

2 Department of Electrical Electronics Engineering, Iran University of Science and Technology, Tehran 16846, Iran

3 Department of Electrical Electronics Engineering, Khaje Nasir Toosi University of Technology, Tehran 19991-43344, Iran; E-Mail: raissi@kntu.ac.ir

4 Department of Electrical Electronics Engineering, Urmia University, Urmia 57159, Iran; E-Mail: s.afrang@urmia.ac.ir

$\dagger$ These authors contributed equally to this work.

* Author to whom correspondence should be addressed; E-Mail: m_kuchaki@iust.ac.ir; Tel.: +98-912-340-5024; Fax: +98-21-7724-0487.

External Editor: Peter Woias

Received: 11 August 2014; in revised form: 22 September 2014 / Accepted: 1 October 2014 / Published: 4 December 2014

Abstract: This paper presents the design and simulation of an improved electro-thermal micromachined pump for drug delivery applications. Thermal actuators, which are a type of Micro Electro Mechanical system (MEMS) device, are highly useful because of their ability to deliver with great force and displacement. Thus, our structure is based on a thermal actuator that exploits the Joule heating effect and has been improved using the springy length properties of MEMS chevron beams. The Joule heating effect results in a difference in temperature and therefore displacement in the beams (actuators). Simulation results show that a maximum force of $4.4 \mathrm{mN}$ and a maximum flow rate of $16 \mu \mathrm{L} / \mathrm{min}$ can be obtained by applying an AC voltage as low as $8 \mathrm{~V}$ at different frequencies ranging from 1 to $32 \mathrm{~Hz}$. The maximum temperature was a problem at the chevron beams and the center shaft. Thus, to locally increase the temperature of the chevron beams alone and not that of the pumping diaphragm:

(1) The air gaps $2 \mu \mathrm{m}$ underneath and above the device layer were optimized for heat transfer.

(2) Release holes and providing fins were created at the center shaft and actuator, 
respectively, to decrease the temperature by approximately $10^{\circ} \mathrm{C}$. (3) We inserted and used a polymer tube to serve as an insulator and eliminate leakage problems in the fluidic channel.

Keywords: MEMS micropump; electro thermal actuator; joule heating; pumping force; flow rate

\section{Introduction}

Currently, the effect of most drugs in the body is considered to be a very important problem. At high concentrations, drugs are toxic, and at low concentrations, they have no therapeutic benefit [1]. With respect to drug sensitivity, the rate of drug delivery cannot be carefully controlled using the conventional injection and oral tablet methods. Thus, problems, such as toxicity or inefficacy, occur; additionally, frequent drug administration and repeated therapy require significant amounts of time and cause patient frustration. Therefore, to more precisely control drug delivery and address the aforementioned problems, a drug delivery system (DDS) is needed. Moreover, with the help of an implantable DDS, the injection pain associated with frequent injections can be relieved, and the risk of contamination or infection associated with the conventional injection method can be avoided [2].

Micro Electro Mechanical System (MEMS) micropumps are the essential components of drug delivery systems (DDS). These micropumps provide the actuation mechanism required to deliver specific volumes of therapeutic agents/drugs from a reservoir. The requirements of a DDS include small size, high reliability, and a minimum flow rate on the order of approximately $10 \mu \mathrm{L}$ per minute or more. Pioneering work on micropumps started in the 1970s, and developments based on microfabrication technology were initiated in the 1980s. The MEMS-based micropump was developed in the 1990s. Typically, a micropump consists of the following components: a diaphragm membrane, a chamber, an actuator, microchannels, microvalves, an inlet, and an outlet. Technically, micropumps are categorized into two types: mechanical and non-mechanical. The mechanical type requires a physical actuator or mechanism to perform the pumping function. In contrast, non-mechanical pumps must transform certain available non-mechanical energy into kinetic energy, which is an inferior mode of operation relative to that of mechanical micropumps. The most popular mechanical micropumps applied in MEMS are piezoelectric, electrostatic, thermopneumatic, electromagnetic, bimetallic, ion conductive polymer film (ICPF), phase change and shape memory alloy (SMA) micropumps $[3,4]$.

Based on the demand for microfluidic systems used in biomedical and chemical analysis applications, the key constraining factors for micro-dosing/drug delivery are a suitable and safe input voltage, high performance, high flow rate, and simple fabrication structure. Each of the aforementioned types of micropumps possesses unique advantages and disadvantages: (a) Although Piezoelectric (PZT) micropumps exhibit high performance, they require a high input voltage. (b) SMA and thermopneumatic micropumps have a low input voltage, but their response time is long [5]. (c) The advantage of an electrostatic micropump is that it can simultaneously mix a variety of doses and then convey the final fluid into micro channels. However, the major shortcomings of electrostatic micropumps are their structural complexity and the high applied voltage required [6]. (d) Electromagnetic micropumps require low voltage, but an external source is needed for actuation, which thus leads to high power consumption 
and heat dissipation. (e) Compared to that required by other types of micropumps, the voltage required by bimetallic micropumps is relatively low; however, in addition to their complex structure, these micropumps are not suitable for operation at high frequencies $(0.5 \mathrm{~Hz})$ [4]. (f) Ion conductive polymer film (ICPF) micropumps offer quite a few advantages, such as low driving voltage and biocompatibility. In addition, these pumps can operate in aqueous environments. The major shortcoming of ICPF micropumps is their weak reproducibility in batch fabrication and their low-frequency (2 Hz) operation [5].

In this paper, the mathematical theory and the design and simulation of electro-thermal micropumps are presented. Compared to previous studies on these types of micropumps, this work is based on a new strategy in which further advantages, such as low die area, high flow rate and force, low applied voltage and structural simplicity, are incorporated. In contrast to traditional micropump designs, which use an out-of-plane pumping diaphragm, our work consists in using an in-plane pump, designed using IntelliSuite software (IntelliSuite, Woburn, MA, USA), with actuators, chevron spring beams, diaphragms, and input/output fluidic valves.

The main idea of the electro-thermal actuator used for the micropump developed in this study is based on the springy property in the chevron beams. In addition, we also etched release holes in the center shaft and used providing fins in the back of the diaphragm for cooling and preventing changes in fluid properties.

The proposed structure was designed using a $500 \mu \mathrm{m}$ thick silicon on insulator (SOI) wafer. The substrate consisted of a $100 \mu \mathrm{m}$ thick device layer, $2 \mu \mathrm{m}$ thick insulator layer and an approximately $398 \mu \mathrm{m}$ thick handle layer, which could be fabricated as a single layer. Because of the simplicity of the fabrication process, this structure will reduce costs related to fabrication and the overall dimensions of the device. The novel structure of our design and the simulation results obtained for the design show good biocompatibility with the requirements for drug delivery. Thus, this structure can be fabricated by deep reactive ion etching (DRIE) on a silicon-on-insulator (SOI) wafer.

\section{A Novel Electro-Thermal Micropump: Design}

According to Figure 1a, the structure of our in-plane micropump consists of three layers: a $100 \mu \mathrm{m}$ thick device layer, a $2 \mu \mathrm{m}$ thick insulator layer and a $398 \mu \mathrm{m}$ thick handle layer, yielding a structure measuring $500 \mu \mathrm{m}$ in total thickness on a SOI wafer; the structure was designed using IntelliSuite software. For the thermal actuator to function as a micropump, a $500 \mu \mathrm{m}$ thick Pyrex glass layer was anodically bonded to the SOI device. Prior to bonding, eight holes were drilled through the Pyrex layer. Four holes were used for electrical connections, whereas the remaining four served as ports for fluidic interconnects. Similar to the $2 \mu \mathrm{m}$ gap underneath the device, a $2 \mu \mathrm{m}$ gap is also maintained above the device. This structure facilitated the motion of the chevron beams and also eliminated the anodic bonding of the chevron beams to the Pyrex layer. To avoid leakage through the $2 \mu \mathrm{m}$ air gap, a Parylene polymer tube was inserted between the leakage paths, as will be discussed in Section 3.4.

The detailed design is illustrated in Figure 1b. The main components of the device layer were two contact pads (in each die half) for electric contact; V-shaped chevron beams, which acted as springs and were in contact with the pads; and a central shaft, which was connected to the diaphragm and amplified the displacement of the actuator. Six chevron beams were placed on either side of the center shaft. With a direct distance of $1200 \mu \mathrm{m}$, the beams were designed to measure $1500 \mu \mathrm{m}$ in length and a cross-sectional area of $10 \mu \mathrm{m} \times 100 \mu \mathrm{m}$ and a rib angle of $2.2^{\circ}$ based on detailed optimization studies [7]. The pump 
diaphragm was $750 \mu \mathrm{m}$ long, $100 \mu \mathrm{m}$ thick, and $50 \mu \mathrm{m}$ wide. The design also featured a $2000 \mu \mathrm{m}$ long, $100 \mu \mathrm{m}$ wide, and $100 \mu \mathrm{m}$ deep fluidic channel along with an inlet/outlet channel valves arrangement for flow rectification.

The operating principle of our micropump is shown in Figure 1c,d. When a differential voltage is applied at the pads, the narrower section of the pump structure (chevron beams measuring $10 \mu \mathrm{m}$ wide) develops a higher resistance to current than the other structures (voltage pads) do. As a result, the power (square of the current times the resistance of the beams) is dissipated in the narrower section, causing it to expand due to induced thermal strain (Joule heating). When heated, the center shaft can only move along its length because the device is symmetrical in nature and the beams are constrained at the ends. This motion of the shaft is further transferred to the pump diaphragm through the lever mechanism. The reciprocating (pumping) motion of the pump diaphragm is obtained by applying an $\mathrm{AC}$ voltage with amplitude of $8 \mathrm{~V}$ and a frequency of $1-32 \mathrm{~Hz}$ to the pads. The inlet/outlet arrangement is used to obtain unidirectional flow. Thus, for half of the cycle, the fluid is siphoned through the inlet channel and then pumped through the exit channel in the other half of the cycle.

Figure 1. (a) Schematic of proposed micropump dies (overall shape) and (b) detailed design. (c) Operating principle of the proposed micropump with fluid suction through the inlet channel in one half of the AC voltage cycle and (d) fluid pumping through the exit channel in another half of the cycle.

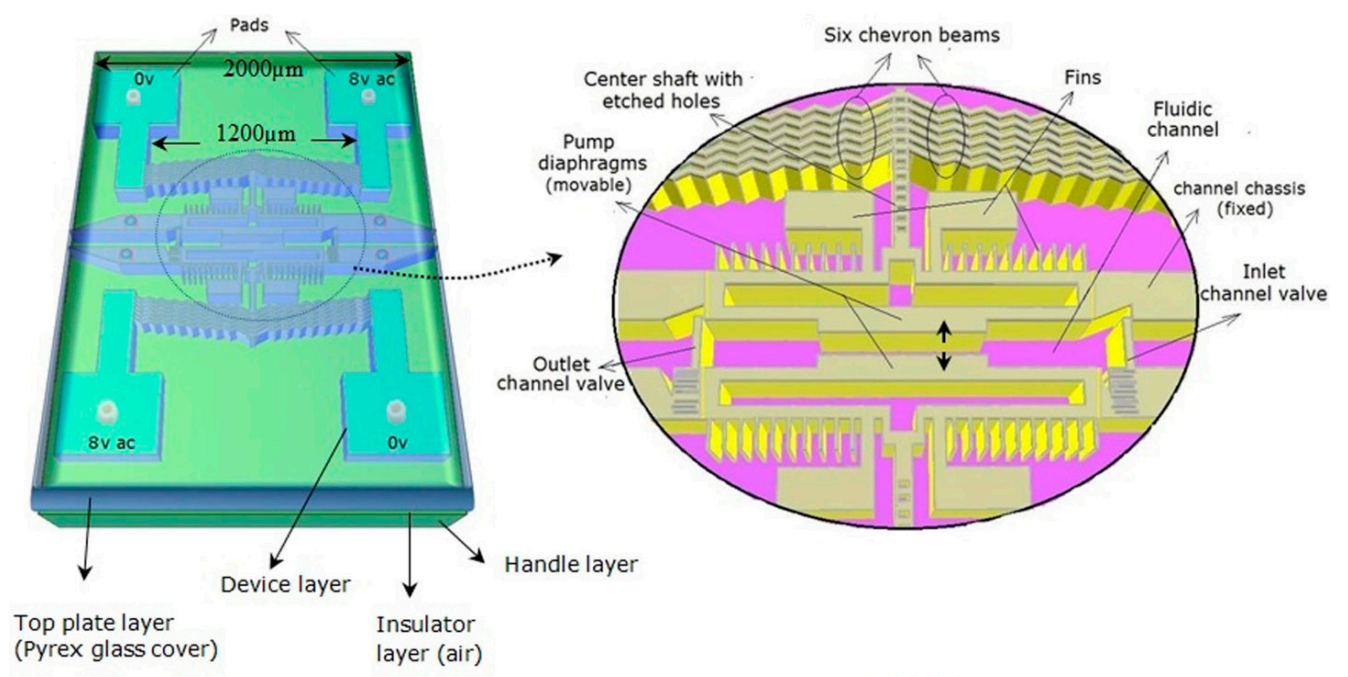

(a)

(b)

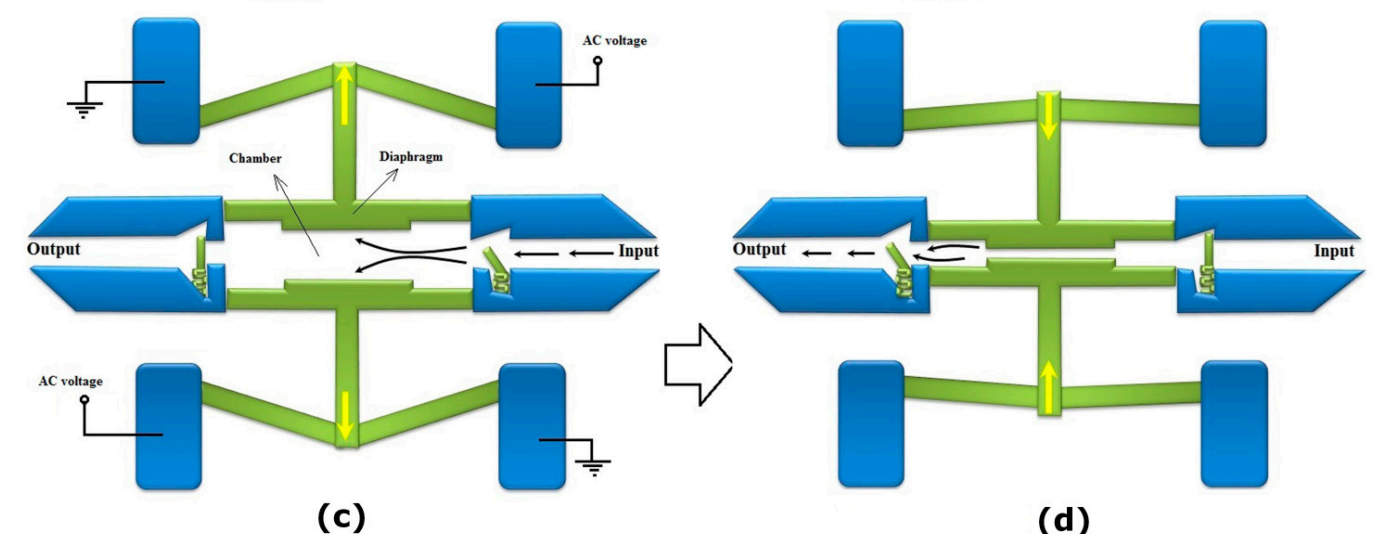

(c)

(d) 


\section{A Novel Electro-Thermal Micropump: Analysis}

Understanding the thermal behavior of the device layer of the system developed is very important. Thus, in this section, we will concentrate on the Joule heating phenomenon on underlying the operating principle of the proposed micropump. The delivery of a drug via the pump depends on the temperature of the chevron beams. For this reason, once the temperature of the beam is known, the displacement and the actuation force of the pump diaphragm can be determined, and then, the flow rate can be estimated. In Sections 3.1, 3.2, 3.3 and 3.4, we will calculate, analyze and discuss the simulation results of the thermal behavior of one beam, the actuation force of the diaphragm, the flow rate of the pump and fluidic flow leakage, respectively. Differential equation solutions and simulations were performed using IntelliSuite and MATLAB software.

\subsection{Thermal Analysis}

In this section, a beam (Figure 2) is analyzed in terms of its electro-thermal properties. In this single beam, when the temperature is different between the ambient temperature and the inside of the beam, the change in the length of the beam can be given by $[8,9]$ :

$$
\Delta L=\alpha \int_{0}^{L} \alpha(T) T(x) d x
$$

where $\alpha(T)$ is the thermal expansion coefficient and is constant for various temperatures. This equation can be simplified as follows:

$$
\Delta L=\alpha \int_{0}^{L} T(x) d x
$$

Figure 2. Conventional single beam with length $2 \mathrm{~L}$ connected to pads with ambient temperature $T s$.

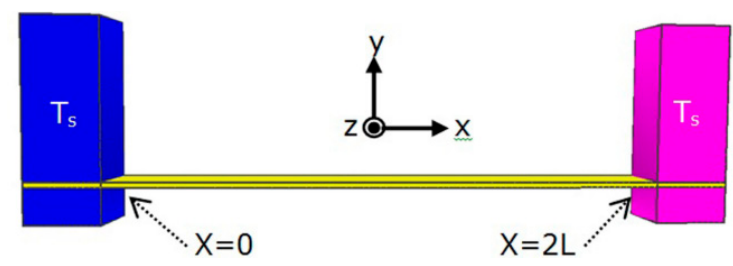

By applying a voltage across the beam, the electrical energy, as a function of current $I$ and resistance $R$, is converted to thermal energy, which induces thermal expansion:

$$
E_{\text {thermal }}=I^{2} R
$$

Before determining the change in the beam and the force generated (in the next section), we should consider the temperature distribution within the beam using the following equation:

$$
k_{T} \frac{d^{2} T}{d x^{2}}+J^{2} \rho=0
$$

where $k_{T}, J$ and $\rho$ are the thermal conductivity, current density and resistivity of the beam, respectively. Both resistivity $\rho$ and thermal conductivity $k_{T}$ change with temperature. Assuming $k_{T}$ is a constant and the resistivity of the beam changes linearly as the temperature varies, $k_{T}$ is assumed to be equal to the thermal conductivity at room temperature, and: 


$$
\rho=\rho_{0}\left[1+\lambda\left(T-T_{s}\right)\right]
$$

where $\rho_{0}$ is the resistivity at $T_{s}$ (ambient or surrounding temperature) and $\lambda$ is the linear temperature coefficient. Equation (5) can be written as follows:

$$
k_{T} \frac{d^{2} T}{d x^{2}}+J^{2} \rho_{0}\left[1+\lambda\left(T-T_{s}\right)\right]=0
$$

The solution to this differential equation is a combination of a homogeneous term and a non-homogenous constant. According to Figure 2 and using the initial conditions $T(x=0$ and $x=2 L)=T_{s}$, the final solution to Equation (6) with $\tau=J \sqrt{\frac{\lambda \rho_{0}}{k_{T}}}$ can be obtained as follows:

$$
T(x)=T_{s}+\frac{1}{\lambda}-\left(\frac{1}{\lambda}-\frac{\left(1-e^{\tau 2 L}\right)}{\lambda\left(e^{-\tau 2 L}-e^{\tau 2 L}\right)}\right) e^{\tau x}-\frac{1}{\lambda} \frac{\left(1-e^{\tau 2 L}\right)}{\left(e^{-\tau 2 L}-e^{\tau 2 L}\right)} e^{-\tau x}
$$

Now, the average temperature in the beam is given by

$$
T_{\text {avg }}=\frac{1}{2 L} \int_{0}^{2 L} T(x) d x
$$

Thus, by substituting Equation (7) into Equation (8), the average temperature can be obtained as follows:

$$
T_{\text {avg }}=\frac{1}{2 L}\left(T_{s}+\frac{1}{\lambda}\right) 2 L-\frac{1}{\tau}\left(\frac{1}{\lambda}-\frac{\left(1-e^{\tau 2 L}\right)}{\lambda\left(e^{-\tau 2 L}-e^{\tau 2 L}\right)}\right)\left(e^{\tau 2 L}-1\right)+\frac{\left(e^{-\tau 2 L}-1\right)}{\lambda \tau} \frac{\left(1-e^{\tau 2 L}\right)}{\left(e^{-\tau 2 L}-e^{\tau 2 L}\right)}
$$

As previously mentioned and according to Figure 3, in our integrated structure, there are six spring chevron beams on either side of the center shaft. With a direct distance of $1200 \mu \mathrm{m}$, the beams measure $1500 \mu \mathrm{m}$ in length with a cross-sectional area of $10 \mu \mathrm{m} \times 100 \mu \mathrm{m}$ and a rib angle of $2.2^{\circ}$. The properties of the silicon substrate and the details of the micropump structure are summarized in Table 1.

Figure 3. Six spring chevron beams measuring $1500 \mu \mathrm{m}$ in length with a cross-sectional area of $10 \mu \mathrm{m} \times 100 \mu \mathrm{m}$ and a rib angle of $2.2^{\circ}$.

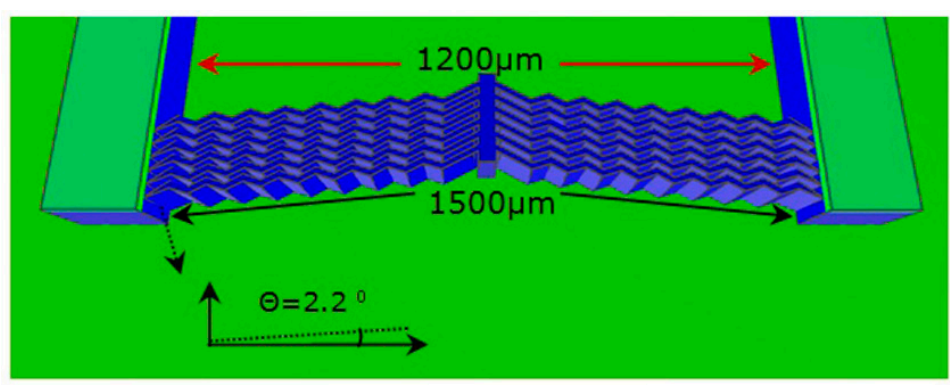

Table 1. Material properties of silicon wafer and detailed design of proposed structure.

\begin{tabular}{cccccccc}
\hline $\begin{array}{c}\text { Length of } \\
\text { beams } \boldsymbol{l}=\mathbf{2} \boldsymbol{L}\end{array}$ & $\begin{array}{c}\text { Applied } \\
\text { voltage } \boldsymbol{V}\end{array}$ & $\begin{array}{c}\text { Current } \\
\text { density } \boldsymbol{J}\end{array}$ & $\begin{array}{c}\text { Resistivity } \\
\boldsymbol{\rho}_{\mathbf{0}}\end{array}$ & $\begin{array}{c}\text { Linear temperature } \\
\text { coefficient [10] } \boldsymbol{\lambda}\end{array}$ & $\begin{array}{c}\text { Thermal conductivity } \\
{[\mathbf{1 1}-\mathbf{1 3}] \boldsymbol{k} \boldsymbol{T}}\end{array}$ & $\begin{array}{c}\text { Ambient } \\
\text { temperature } \boldsymbol{T}_{\boldsymbol{s}}\end{array}$ & $\boldsymbol{\tau}=\boldsymbol{J}$ \\
\hline $1500 \mu \mathrm{m}$ & $8 \mathrm{~V}$ & $5.1 \times 103 \mathrm{~A} / \mathrm{cm}^{2}$ & $0.01 \mathrm{ohm}-\mathrm{cm}$ & $1.25 \times 10^{-4} /{ }^{\circ} \mathrm{C}$ & $1.57 \mathrm{~W} / \mathrm{cm}-{ }^{\circ} \mathrm{C}$ & $2 \boldsymbol{k}_{\boldsymbol{T}}$ \\
\hline
\end{tabular}


According to Ohm's law and the relations $I=J \cdot A, R=\rho l / A$ and $J=I / A=V / \rho l$, and based on the details presented in Table 1, solving Equations (7) and (9) in MATLAB yields the following maximum and average temperatures $T_{\max }$ and $T_{a v g}$, respectively:

$$
T_{\max }=T(x=L)=477^{\circ} \mathrm{C} \text { and } T_{a v g}=328^{\circ} \mathrm{C}
$$

We used the IntelliSuite software program to analyze the static and dynamic behaviors of the proposed structure and visualize the results.

(1) In the static analysis, the structure (half die) was analyzed using the IntelliSuite software program. On the voltage pads, constant temperature $\left(27^{\circ} \mathrm{C}\right)$ boundary conditions were defined. The voltage on one of the pads was fixed at $0 \mathrm{~V}$, whereas on the other pad, a voltage of $8 \mathrm{~V}$ was applied. This structure was designed using Intellimask (IntelliSuite, Woburn, MA, USA) and 3D Builder modules and later imported into the thermo-electro-mechanical module. Appropriate materials properties were defined, and the structure was then meshed with a maximum mesh size of $40 \mu \mathrm{m}$ to generate approximately 18,604 elements.

The simulation results presented in Figure 4 show the maximum temperature attained in this case. A rise in the temperature of the device above the ambient temperature is a result of Joule heating occurring in the chevron beams. As previously mentioned, when a differential voltage is applied to the pads, the narrower section of the pump structure (chevron beams measuring $10 \mu \mathrm{m}$ wide) develops a higher resistance to current than the rest of the structure (voltage pads).

Figure 4. Geometry and boundary conditions of the proposed structure with simulation results obtained for temperature distribution (for half device only).

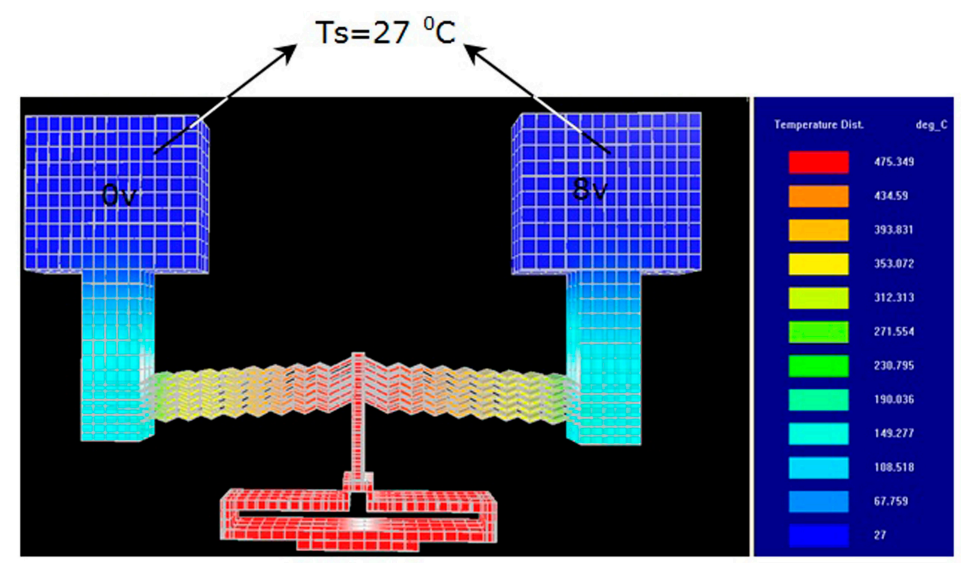

As a result, the power (square of the current times the resistance of the beams) is dissipated in the narrower section, causing it to expand due to induced thermal strain (Joule heating). Because all the beams are identical, the resistance through the beams will be the same, resulting in uniform heating; furthermore, because symmetrical temperature boundary conditions exist, a uniform temperature distribution is also created. Therefore, the maximum temperature is obtained in the center shaft and is equal to $475.5^{\circ} \mathrm{C}$, which is similar to the result, obtained using Equation (10).

Specifically, the maximum temperature was noted at the intersection of the chevron beams and the center shaft. Therefore, the pump cannot be used for its intended application in its present form. The potency and stability of medical drugs are known to degrade at such high temperatures, which might create a problem by changing the sensitive fluid properties in the micropump flow path. 
To solve this problem, we proposed certain design modifications to reduce the heat flow and temperature distribution at the flow path while maintaining the high temperature at the $V$ beams to create greater displacement:

1. One of the viable options is to optimize the air gap underneath and above the device, which would help locally increase the temperature of the chevron beams alone and not that of the pumping diaphragm (that is in contact with the pumping fluid). Thus, in ongoing research, the air gap plays a crucial role in determining the temperature of the chevron beams. From the chevron beams, heat is initially conducted to the air gap $(2 \mu \mathrm{m})$ underneath and $(2 \mu \mathrm{m})$ above the device and then to the handle layer and top plate layer. According to Figure 5a, the boundary conditions on the voltage pads are similar to those shown in Figure 4. In addition, the boundary condition of heat convection was defined on the bottom and top of the device layer. The structure was meshed with a maximum mesh size of $40 \mu \mathrm{m}$ to generate approximately 18,604 elements. The simulation results presented in Figure 5a,b illustrate a maximum temperature of $375^{\circ} \mathrm{C}$ at the center shaft, an average temperature of $260{ }^{\circ} \mathrm{C}$ and a temperature of $180{ }^{\circ} \mathrm{C}$ at the pump diaphragm for the same input voltage used to generate the results shown in Figure 4.

2. We developed another design by providing fins and release holes in the back of the diaphragm and center shaft, respectively (Figure 5b). The addition of fins and etching holes throughout the central rod provide a significant reduction in temperature. This design reduces the temperature of the center shaft and pump diaphragm by approximately $10{ }^{\circ} \mathrm{C}$.

3. Although the temperatures obtained in the previous section (i) are still higher than the sustainable limits of medical drugs, the temperature at the contact point (i.e., at the diaphragm) is slightly above the ambient temperature.

Inserting a polymer tube (as an insulator) not only solves the high-temperature problem at the contact of the pump diaphragm but also allows for a higher temperature at the center shaft and thus greater displacement. A biocompatible polymer (such as Parylene) was used as a tube material because it can be conformably deposited and patterned $[14,15]$. Thus, we can use a Parylene tube as an insulating thermoplastic coating on the diaphragm, which prevents heat transfer to the fluid flow and transfers the force and motion of the thermal actuators to the fluid. (The fabrication details of the Parylene tube and the added benefit of eliminating leakage problems will be described in Section 3.1). As previously mentioned, the temperature at the pump diaphragm was significantly reduced to $180{ }^{\circ} \mathrm{C}$, which is below the melting temperature of Parylene $\left(290^{\circ} \mathrm{C}\right)$.

(2) In the dynamic analysis, we analyzed the operation of the structure at different frequencies of the applied input voltage. In this case, we used the thermo-electro-mechanical module to visualize the simulation results obtained for a temperature variation in the center shaft and its dynamic behavior as a function of different applied frequencies. As shown in Figure 5c, we applied a reference temperature of $180{ }^{\circ} \mathrm{C}$ to the pump diaphragm (obtained in Figure 5a) instead of convective boundary conditions. Moreover, we applied an $\mathrm{AC}$ voltage with an amplitude of $8 \mathrm{~V}$ and different frequencies in the range of $1-400 \mathrm{~Hz}$.

According to Figures 6 and 7, the simulation results show that in the frequency range of 1-32 Hz, the maximum temperature of the center shaft is constant at a value of approximately $\sim 375{ }^{\circ} \mathrm{C}$, determined with an accuracy of $99 \%\left(\sim 5^{\circ} \mathrm{C}\right.$ error $)$, whereas in the other frequency ranges, the waveforms are destroyed. 
According to Table 2, the temperature is not constant and will decrease. Thus, in this study, the frequency range $1-32 \mathrm{~Hz}$ is considered acceptable.

In contrast to conventional electro-thermal actuator designs, which require higher voltages and introduce higher temperatures, our structure is simpler and uses a lower voltage $(8 \mathrm{~V})$ over suitable frequencies. The design also keeps the diaphragm cool to avoid heat flow and to prevent any changes in fluid properties $[9,16]$.

Figure 5. Temperature distribution ( $T_{\max }$ of center shaft is $375^{\circ} \mathrm{C}$, average temperature is $260^{\circ} \mathrm{C}$ and pump diaphragm temperature is $180^{\circ} \mathrm{C}$ ) of modified structure with (a) boundary conditions of heat convection and (b) fins added to the back of the diaphragm and holes etched in the center shaft. (c) Applying AC voltage to the proposed structure to demonstrate dynamic behavior.

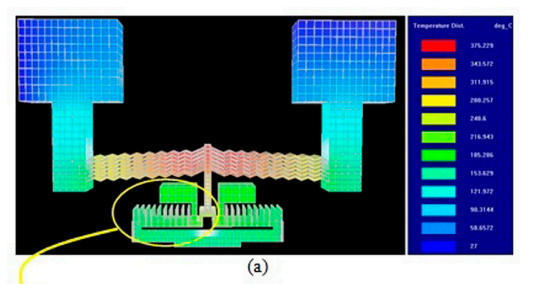

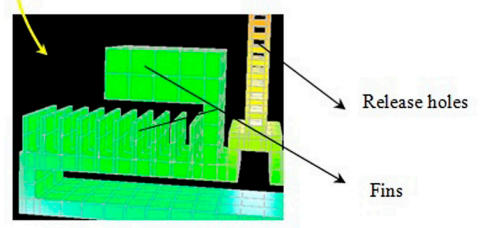

(b)

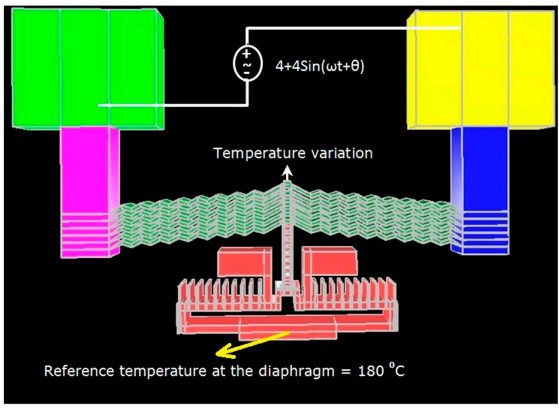

(c)

Figure 6. Dynamic behavior of the structure shown in Figure 5c: (a) Input voltage applied with a frequency of $f=1 \mathrm{~Hz}$. (b) Temperature variation in the center shaft (max Temperature $=375^{\circ} \mathrm{C}$ ).

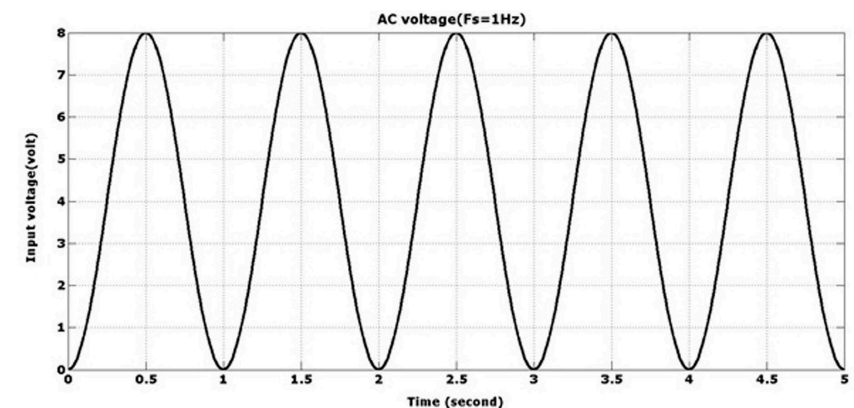

(a)

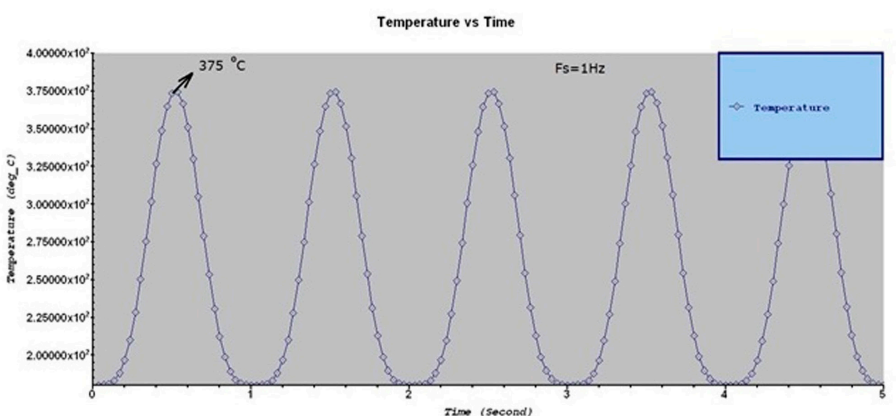

(b) 
Figure 7. Temperature variation of the center shaft shown in Figure 5c: (a) Max Temperature $=$ $373{ }^{\circ} \mathrm{C}$ with $f=20 \mathrm{~Hz}$. (b) Max Temperature $=370{ }^{\circ} \mathrm{C}$ with $f=32 \mathrm{~Hz}$. (c) Max Temperature $=$ $351{ }^{\circ} \mathrm{C}$ with $f=50 \mathrm{~Hz}$. (d) Max Temperature $=326^{\circ} \mathrm{C}$ with $f=100 \mathrm{~Hz}$. (e) Max Temperature $=$ $295^{\circ} \mathrm{C}$ with $f=200 \mathrm{~Hz}$.
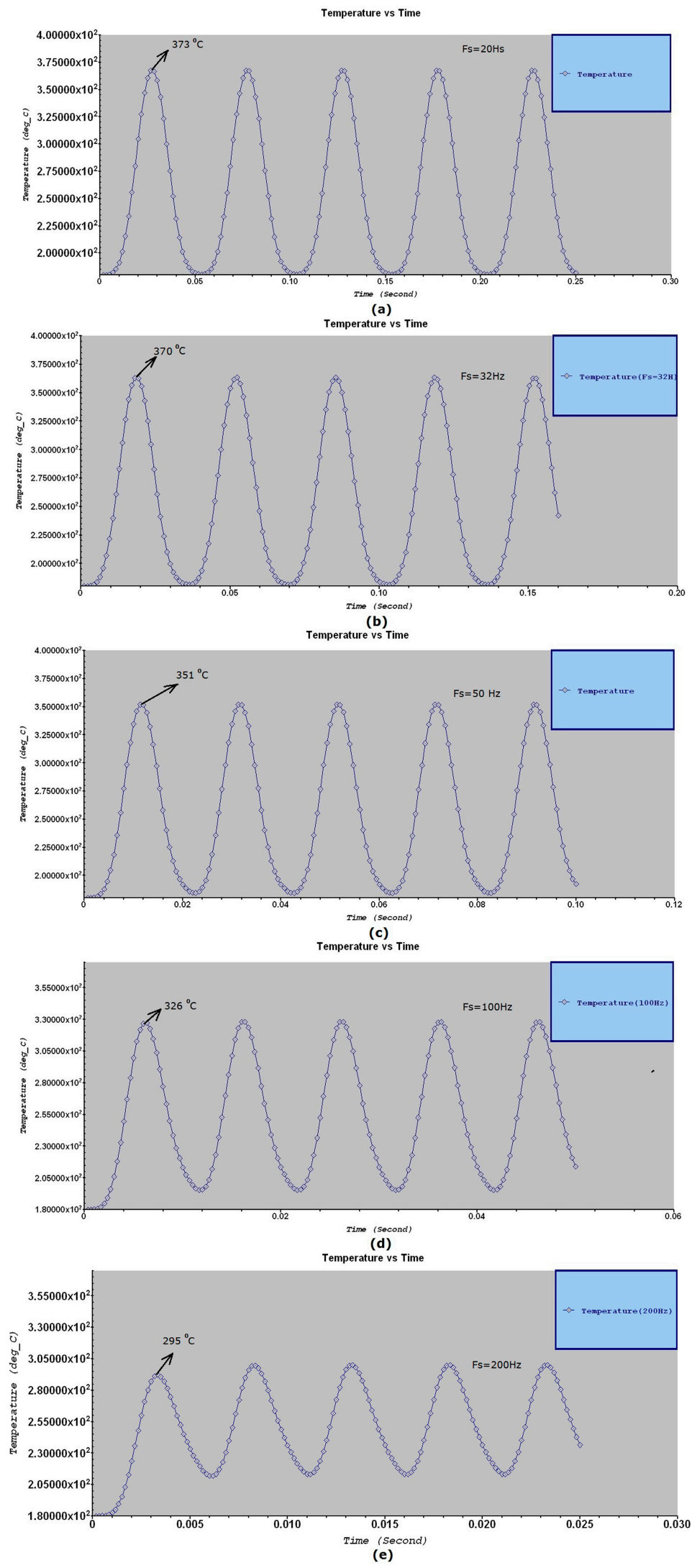
Table 2. Temperature variation of the center shaft versus frequency of applied voltage.

\begin{tabular}{ccccccccccc}
\hline Frequency (Hz) & 1 & 5 & 10 & 20 & 32 & 50 & 100 & 200 & 300 & 400 \\
\hline Temperature $\left({ }^{\circ} \mathbf{C}\right)$ & 375 & 375 & 375 & 373 & 370 & 351 & 326 & 295 & 269 & 250 \\
\hline
\end{tabular}

\subsection{Pumping Force Analysis}

To determine the flow rate of the micropump, it is necessary to estimate the pumping force. When a voltage is applied to the pads, the chevron beams will expand due to Joule heating, which will move the diaphragm and exert a force on the fluid. The maximum force is given by [17],

$$
F=A \sigma
$$

where $F$ is the force at the actuator, $A$ is the cross-sectional area of the beam and $\sigma$ is the coefficient of thermal expansion. Because the strain $\varepsilon$ is given by $\varepsilon(x)=\alpha T(x)$ and the axial stress $\sigma$ with Young's modulus $E$ is given by $\sigma=E \varepsilon$, using Equations (2) and (8), the force developed by the actuator with beam springy length $l=2 L$ is given by,

$$
F=A \sigma=A E \varepsilon=A E \alpha T_{a v g} l
$$

According to Figure 8a, to obtain a more accurate calculation and because the beam is designed with a rib angle of $2.2^{\circ}$, it is necessary to analyze the force obtained to balance all forces. At points 1 and 3 , the resultant force is absorbed by the fixed pad wall. Along the $x$ direction of node 2 ,

$$
\sum F_{x}=\frac{F_{t}}{2} \cos \theta+\left(-\frac{F_{t}}{2} \cos \theta\right)=0
$$

and along the $y$ direction,

$$
\sum F_{y}=\frac{F_{t}}{2} \sin \theta+\frac{F_{t}}{2} \sin \theta=F_{t} \sin \theta
$$

For $N$ chevron beams, the total force is:

$$
F_{\text {total }}=N F_{t} \sin \theta
$$

Figure 8. (a) Diagram of forces acting on a chevron beam ( $V$ form). (b) Simulation results of obtained displacement $(9.6 \mu \mathrm{m})$ of pump diaphragm.

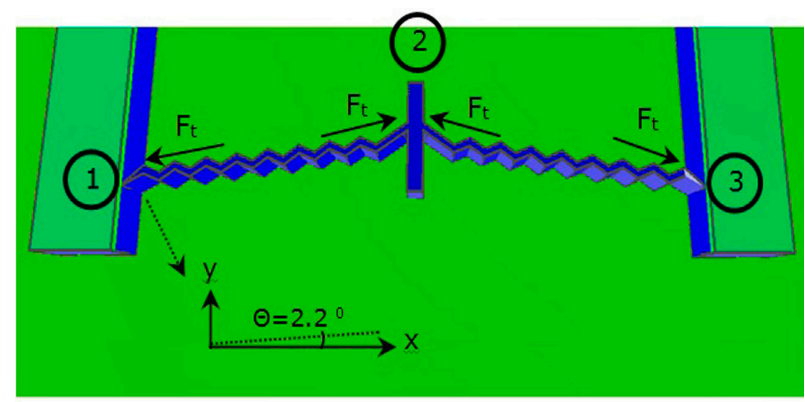

(a)

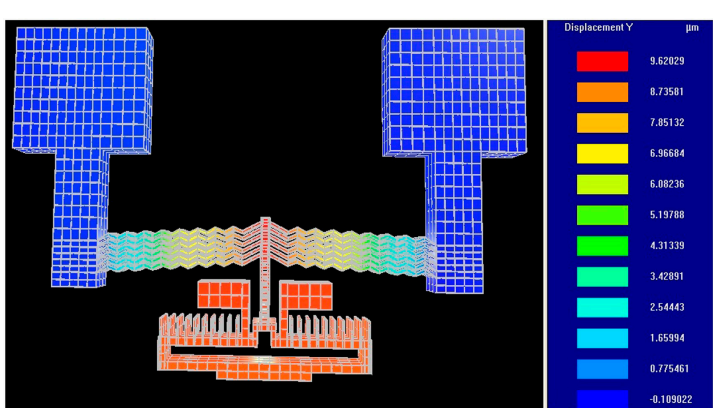

(b)

According to Figure 5a $\left(T_{\text {avg }}=260{ }^{\circ} \mathrm{C}\right)$ and using Equation (12) with $\theta=2.20, L=750 \mu \mathrm{m}$ and data listed in Table 3, we obtained the following value,

$$
F_{t}=19.1 \cdot \mathrm{mN}
$$


and the total force in the $y$ direction for 6 beams will be,

$$
F_{\text {total }}=N F_{t} \cdot \sin \theta=6 \times 19.1 \times \sin \left(2.2^{\circ}\right)
$$

In addition, Figure $8 \mathrm{~b}$ shows that the resulting displacement of the pump diaphragm is approximately $9.6 \mu \mathrm{m}$.

In contrast to the design described in a previous study [16], our structure with a beam springy length $L=750 \mu \mathrm{m}$ uses a lower voltage of $8 \mathrm{~V}$. The obtained force is also several times higher than that obtained in comb drive structures $[18,19]$.

Table 3. Material properties of silicon in the chevron beams.

\begin{tabular}{cccc}
\hline $\begin{array}{c}\text { Cross sectional of } \\
\text { beams } \boldsymbol{A}\end{array}$ & $\begin{array}{c}\text { Young's Modulus } \\
\boldsymbol{E}\end{array}$ & $\begin{array}{c}\text { Coefficient of thermal } \\
\text { expansion } \boldsymbol{\alpha}\end{array}$ & $\begin{array}{c}\text { number of chevron } \\
\text { beams } \boldsymbol{N}\end{array}$ \\
\hline $1 \times 10^{-5} \mathrm{~cm}^{2}$ & $169 \times 10^{5} \mathrm{~N} / \mathrm{cm}^{2}$ & $2.9 \times 10^{-6} \mathrm{~K}^{-1}$ & 6 \\
\hline
\end{tabular}

\subsection{Flow Rate Analysis}

To estimate the flow rate of a pump with a nozzle/diffuser arrangement, the pressure loss through the nozzle/diffuser must be determined. The pressure loss depends on the inlet area of the nozzle and the exit area of the nozzle. However, we can still estimate the maximum flow rate (for the corresponding force) by replacing the nozzle/diffuser arrangement with check valves. For opening and closing the inlet and outlet of the fluid channel, we proposed and used check valves with a spring mode structure. Cheng and Tseng designed check valves using a spring design called the compliant orthoplanar spring [20]. Each check valve consisted of a $1 \mathrm{~mm}$ circular plate suspended on four bridge springs. Similarly, as shown in Figure 9a, our structure has a $100 \mu \mathrm{m} \times 100 \mu \mathrm{m}$ movable area and is fixed and connected via a spring beam to the channel chassis (one bridge).

The simulation results show that a pressure of $0.1 \mathrm{MPa}$ with a $1 \mathrm{mN}$ pumping force (according to the pressure equation $P=F / A$ ) is needed to open/close the fluid channel to displace the check valve by approximately $31.7 \mu \mathrm{m}$.

Figure 9. (a) Geometry of proposed check valve. (b) Simulation result showing $31.7 \mu \mathrm{m}$ displacement with an applied $1 \mathrm{mN}$ pumping force.

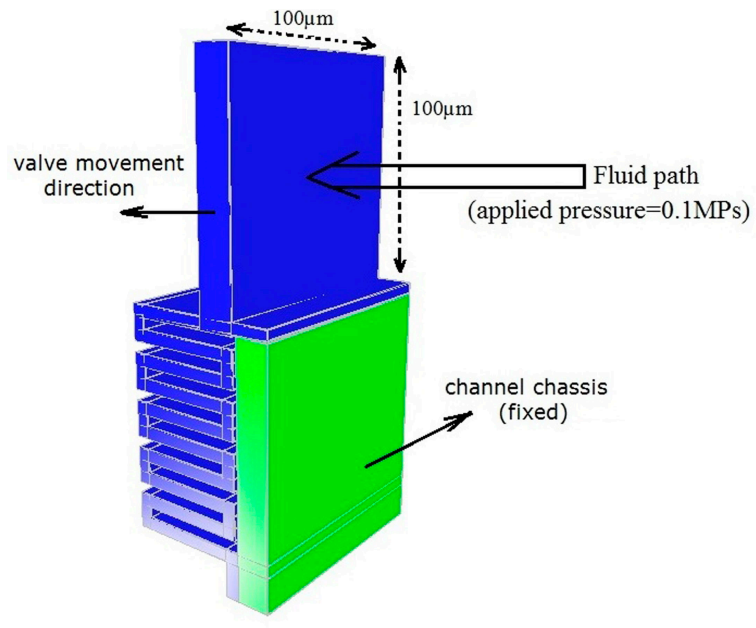

(a)
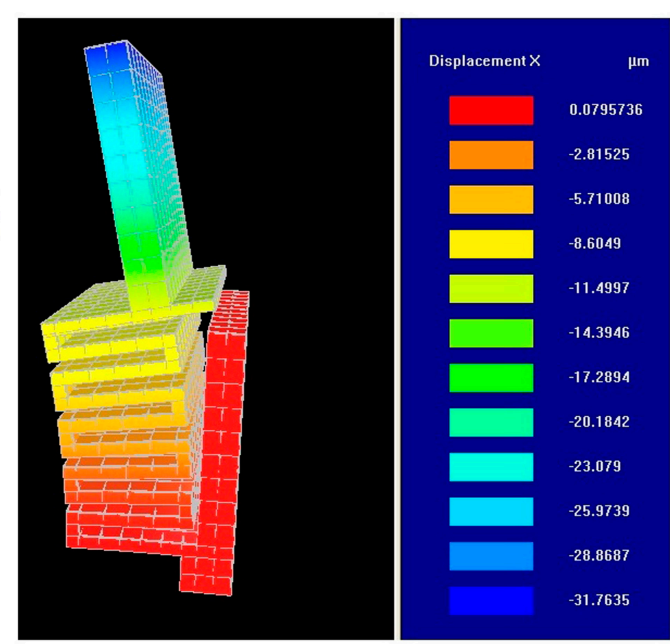

(b) 
To estimate the flow rate of the pump based on the obtained force of $3.4 \mathrm{mN}$ (calculated by subtracting $1 \mathrm{mN}$ force dissipation from $4.4 \mathrm{mN}$ total force), the pump system can be modeled as a piston moving in a cylindrical vessel with a pipe attached to the bottom (Figure 10). The previously described micropump (Figure 1) essentially consisted of a diaphragm and a nozzle/diffuser arrangement. For the device to operate as a pump, an AC voltage with frequency of $1-32 \mathrm{~Hz}$ is applied to the pads. For half of the cycle, the diaphragm deflects and pumps the fluid through the exit channel. For the other half of the cycle, the diaphragm returns to its initial position, during which fluid is siphoned through the inlet channel. Thus, the diaphragm exerts a periodic force $\mathrm{F}$ on the fluid.

Figure 10. Piston-cylinder model of micropump with inlet/outlet.

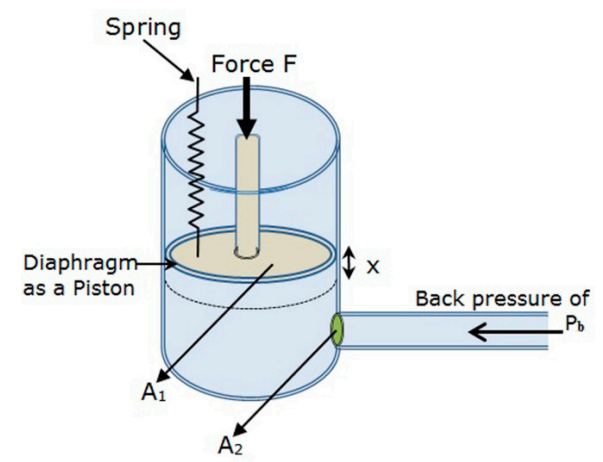

According to Figure 10, the piston moves through the cylinder, which has the same volume as the pump chamber. A damping factor was introduced to make the system critically damped, thereby removing oscillations in the system. Thus, by introducing the damping term and creating a lumped parameter model of the system, the force balance equation of the model is,

$$
m \ddot{x}+b \dot{x}+k x+p_{1} A_{1}=F
$$

where $x$ is the displacement of the piston, $b$ is the damping factor $(2 \sqrt{\mathrm{km}})$ required to remove oscillations in the system, $m$ is the mass of the piston, $k$ is the spring constant, $p_{1}$ is the pressure below the piston, $\mathrm{A}_{1}$ is the cross-sectional area of the piston, and $\mathrm{F}$ is the force acting on the piston. To determine the final differential equation, we use the Bernoulli and Darcy-Weisbach equations (for a liquid such as insulin) [21]:

$$
\begin{gathered}
p_{2}+\frac{\rho_{l} \dot{y}^{2}}{2}=p_{1}+\frac{\rho_{l} \dot{x}^{2}}{2} \\
\Delta p=\lambda_{\mathrm{v}} \frac{1}{D} \frac{\rho_{l}}{2} \times \dot{y}^{2}=k_{2} \dot{y}^{2}
\end{gathered}
$$

where $\dot{y}$ is the outlet flow velocity, $\rho_{l}$ is the density of the liquid, $\lambda_{v}$ is the pipe friction coefficient, $D$ is the diameter and $p_{2}$ is the outlet pressure. The outlet pressure should be able to overcome the pressure drop across the catheter $(\Delta p)$ and the back pressure $\left(p_{b}\right)$ :

$$
p_{2}=\Delta p+p_{b}
$$

The resulting dynamic Equation (18) for the micropump takes the form of a nonlinear lumped model approximation of an ordinary differential equation (ODE):

$$
m \ddot{x}+b \dot{x}+k x+\left(p_{b}+k_{2} \dot{y}^{2}+\frac{\rho_{l} \dot{y}^{2}}{2}-\frac{\rho_{l} \dot{x}^{2}}{2}\right) A_{1}=F
$$


Using a volumetric equation $\left(A_{1} \dot{x}=A_{2} \dot{y}\right)$, the final differential equation will be,

$$
m \ddot{x}+b \dot{x}+k x+\left[p_{b}+\left(k_{2}\left(\frac{A_{1}}{A_{2}}\right)^{2}+\frac{\rho_{l}}{2}\left(\frac{A_{1}}{A_{2}}\right)^{2}-\frac{\rho_{l}}{2}\right) \times \dot{x}^{2}\right] A_{1}=F
$$

Flow rate $=A_{1} \dot{x}$

Equation (23) is the governing equation for the exit and inlet channels of the pump. Table 4 summarizes the nomenclatures and the values for the terms in Equation (23). This equation states the correlation between the fluid displaced by the pump and different parameters such as the geometry of the pump, mass of the diaphragm, applied force, stiffness $k$ (calculated as a ratio of the force to the displacement), and frequency of the applied force (Table 4).

Table 4. Nomenclature of value parameters used in Equation (23) for solving with MATLAB software.

\begin{tabular}{cccccccc}
\hline $\begin{array}{c}\text { Density of } \\
\text { silicon } \boldsymbol{d}\end{array}$ & $\begin{array}{c}\text { Mass of } \\
\text { Diaphragm } \boldsymbol{m}\end{array}$ & $\begin{array}{c}\text { Stiffness of } \\
\text { diaphragm } \boldsymbol{k}\end{array}$ & $\begin{array}{c}\text { Back } \\
\text { pressure } \boldsymbol{p}_{\boldsymbol{b}}\end{array}$ & $\begin{array}{c}\text { Density of fluid } \\
\text { (insulin) } \boldsymbol{\rho}_{\boldsymbol{l}}\end{array}$ & $\begin{array}{c}\text { Area of } \\
\text { piston } \boldsymbol{A}_{\mathbf{1}}\end{array}$ & $\begin{array}{c}\text { Area of } \\
\text { outlet } \boldsymbol{A}_{\mathbf{2}}\end{array}$ & $\begin{array}{c}\text { Force of } \\
\text { actuator } \boldsymbol{F}\end{array}$ \\
\hline $2.3 \mathrm{~g} / \mathrm{cm}^{3}$ & $8.6 \mu \mathrm{g}$ & $354 \mathrm{~N} / \mathrm{m}$ & $8 \mathrm{~mm} \mathrm{hg}$ & $1 \mathrm{~g} / \mathrm{cm}^{3}$ & $750 \times 100 \mu \mathrm{m}^{2}$ & $100 \times 100 \mu \mathrm{m}^{2}$ & $3.4 \mathrm{mN}$ \\
\hline
\end{tabular}

The obtained differential Equation (23) was evaluated and solved by numerical methods in MATLAB (ode45) to determine the flow rate of a liquid given by Equation (24). By applying a sinusoidal voltage, the value of the input force $F$ takes the form $F \sin (\omega t)$, where the term $\omega$ is the angular frequency of the input voltage.

As previously mentioned and according to the Table 2, a sinusoidal input voltage with an amplitude of $8 \mathrm{~V}$ and maximum frequency of $32 \mathrm{~Hz}$ can be applied to our structure and can be used to solve Equation (23).

Figure 11 shows the simulation results of the estimated flow rate of the micropump obtained using Equation (24). With minimum and maximum frequencies of 0 and $32 \mathrm{~Hz}$, respectively, the obtained flow rate will be approximately $\sim 0$ and $8 \mu \mathrm{L} / \mathrm{min}$ for half of the proposed die structure. Because we have a symmetrical structure, the maximum flow rate will be approximately $16 \mu \mathrm{L} / \mathrm{min}$. Figure 12 shows the simulation results obtained for various flow rates of the proposed micropump versus the applied frequency. The figure suggests good performance and linearity up to $32 \mathrm{~Hz}$.

Figure 11. (a) Flow rate obtained at $\sim 0 \mu \mathrm{L} / \mathrm{min}$ with dynamic behavior and $\mathrm{fs}=0 \mathrm{~Hz}$.

(b) Flow rate obtained at $\sim 8 \mu \mathrm{L} / \mathrm{min}$ (half die) with dynamic behavior and fs $=32 \mathrm{~Hz}$.

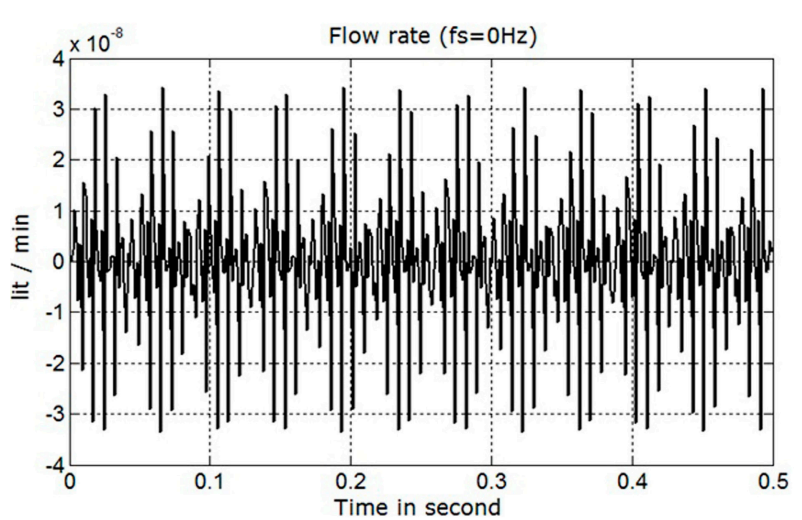

(a)

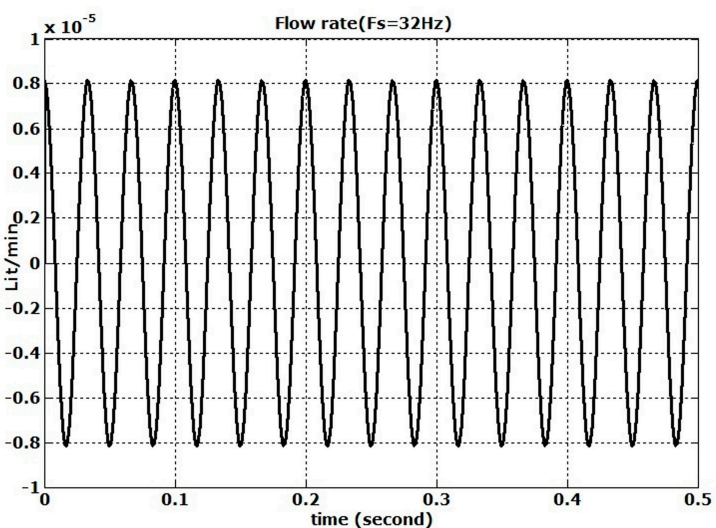

(b) 
Figure 12. Flow rate $(0-16 \mu \mathrm{L} / \mathrm{min})$ versus applied frequency $(0-32 \mathrm{~Hz})$.

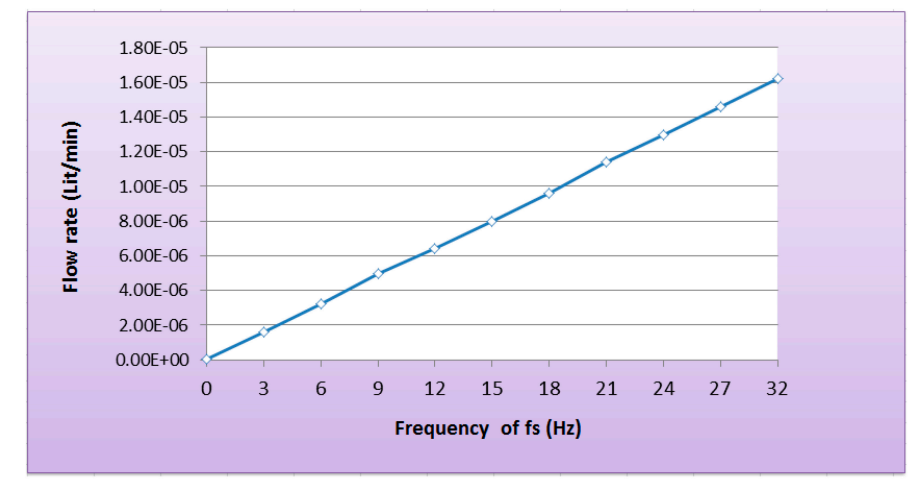

This result is highly intuitive because the flow rate depends on the force, which in turn depends on the average temperature of the chevron beams and, finally, the frequency of the sinusoidal input voltage. The flow rate depicted in Figure $11 \mathrm{~b}$ is the maximum delivery that can be achieved for the proposed in-plane micropump with good linearity over the frequency range of $0-32 \mathrm{~Hz}$ (Figure 12). It is evident that the obtained flow rate is high and can be linearly controlled with an applied frequency, in contrast to designed described in previous studies [6,22].

\subsection{Fluid Flow Leakage}

As mentioned previously, to accommodate the motion of the moving parts in the pump layer (i.e., actuator, diaphragm, and check valves), a micron-sized gap was provided up and down the pump with a glass plate and handle layer, respectively. This design gave rise to some performance issues related to fluid leakage through this $2 \mu \mathrm{m}$ gap. The flow path of the fluid was from the inlet valve through the pump chamber and towards the outlet through the outlet valve. The fluid was pressurized in the pump chamber by the in-plane motion of the diaphragm. Thus, the majority of the fluid would move towards the outlet valve, but due to the gap provided between the pump die and the top cover plate and bottom handle layer, some fluid would also leak through this gap.

Thus, it had to be ensured that the fluid would avoid the electro-thermal actuator (its temperature of $180{ }^{\circ} \mathrm{C}$ ) and the electrical connections to operate the pump. Reducing the size of the gap was not an option because it would have stalled or limited the motion of the moving diaphragm due to friction. The actual physical separation of the fluid from the pump structure was concluded to be the best option. This separation could be achieved by enclosing the fluid in a type of flexible tube running between the vibrating actuators $[14,15]$. Parylene was used as a suitable material for this type of tube structure. Due to its physical properties and low Young's modulus $(3 \mathrm{GPa}$, which is approximately 60 times less than that of silicon), Parylene exhibits excellent mechanical properties, i.e., high tensile and yield strength, biocompatibility, ease of manufacturing and sufficient deformation under small loads.

A special technique for manufacturing enclosed Parylene microchannels was used in this study. Parylene is deposited on a mold and on a flat surface. The molded Parylene is released from the mold and bonded to the flat Parylene layer, forming a free-standing, tube-like structure.

According to the process suggested (in Figure 13), Parylene can be evaporated over a deep reactive-ion etching (DRIE) silicon mold already deposited with a layer of nickel or oxidized silicon to form a layer of silicon dioxide. This nickel or oxide layer is then etched away using the appropriate chemical agents. 
The reasons for using a polymer tube as a covering for the pump chamber are as follows:

1. The tube not only fits into the narrow, trench-like structure in between the silicon $V$-beam actuators but also prevents contact between the fluid and the silicon actuators and prevents fluid leakage.

2. The tube serves as an insulating material that prevents the transmission of heat from the thermal actuators to the enclosed fluid.

Figure 13. Process flow diagram for the lower portion of the Parylene microtube $[15,23]$.

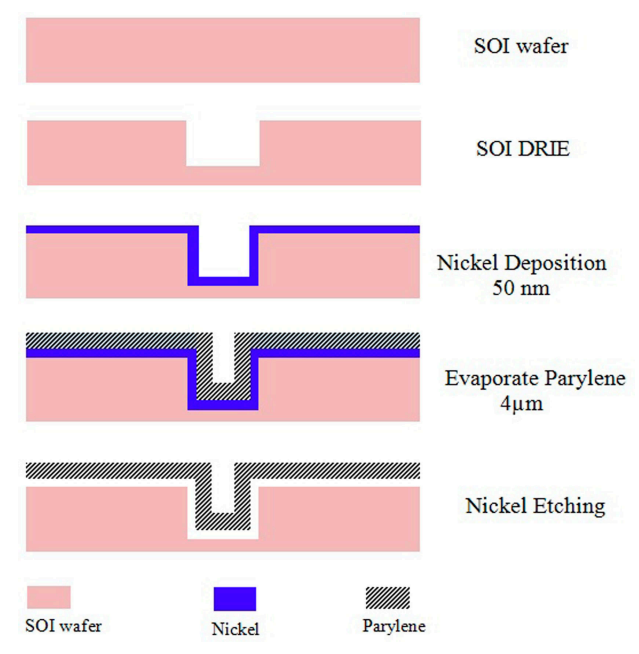

\section{Conclusions}

The design and analysis of an improved in-plane electro-thermal micropump was presented. Our work was generally based on a SOI MEMS structure featuring three layers: a device layer, an insulator layer and a handle layer with a Pyrex top plate. The device layer consisted of two contact pads (in each half die) for electrical contact; six V-shaped chevron beams (in each half die) in contact with the pads; a central shaft, which was connected to the diaphragm and amplified the displacement of the actuator; and a fluidic channel with a nozzle/diffuser and channel valves for flow rectification. In the proposed structure, the thermal actuator operated by the Joule heating effect in the MEMS chevron beams. We improved the structure of this actuator using the spring properties of the chevron beams to increase the required force and flow rate. To prevent the sensitive properties of the fluid from being altered in the fluidic channel with the increasing temperature of the diaphragm, (1) we created a $2 \mu \mathrm{m}$ gap up and down the device layer to transfer heat and reduce the temperature (to $180^{\circ} \mathrm{C}$ ). (2) We also etched release holes in the center shafts and used providing fins in the actuator to cooling the device. (3) Medical drugs cannot withstand the aforementioned high temperatures of the diaphragm; thus, we used a Parylene tube as an insulating thermoplastic coating on the diaphragm. The tube not only prevents heat transfer to the fluid flow and transfers the force and motion of the thermal actuators to the fluid but also eliminates leakage problems. With these modifications, when a differential voltage of $8 \mathrm{~V}$ was applied to the pads, the static ( $\mathrm{fs}=0 \mathrm{~Hz}$ ) and dynamic ( $\mathrm{fs}=1-32 \mathrm{~Hz}$ ) simulation results showed that with an average temperature of $260{ }^{\circ} \mathrm{C}$, the maximum pumping force and flow rate reached values of approximately $4.4 \mathrm{mN}$ and $16 \mu \mathrm{L} / \mathrm{min}$, respectively (Table 5). Our analysis also showed good compatibility between the simulation and numerical results.

The distinctive features of our in-plane electro-thermal micropump are summarized as follows (Table 6): 
- High force and low voltage compared to designs proposed in previous studies [16,24].

- Lower temperature than actuated switches operating based on the Joule heating effect $[25,26]$.

- Cooling system for reducing the temperature of the pump diaphragm to prevent changing the fluid's properties.

- A good insulator material, such as a Parylene tube, for eliminating heat transfer from the diaphragm to the fluidic channel and preventing leakage problems.

- Good linear relation between obtained flow rate and applied frequency of voltage.

- With this linearity, we can obtain good control over the flow rate using frequency-divided circuits.

- Simple and affordable structure for fabrication.

- A die area smaller than that of previously reported designs [6,22,27].

Table 5. Features of the proposed micropump structure [28].

\begin{tabular}{ll}
\hline Descriptions & Features \\
\hline Structure type & SOI (three layers) \\
Chip size & $2000 \mu \mathrm{m} \times 2300 \mu \mathrm{m} \times 100 \mu \mathrm{m}$ \\
Number of spring chevron beams & 6 \\
Length of chevron beams & $1500 \mu \mathrm{m}$ \\
Applied voltage & $8 \mathrm{~V}$ \\
Maximum operating frequency of applied sinusoidal voltage & $1-32 \mathrm{~Hz}$ \\
Maximum temperature & $375^{\circ} \mathrm{C}$ \\
Average temperature & $260{ }^{\circ} \mathrm{C}$ \\
Maximum Pumping force & $4.4 \mathrm{mN}$ \\
Maximum flow rate for total structure & $16 \mu \mathrm{L} / \mathrm{min}$ \\
\hline
\end{tabular}

Table 6. Comparison of the proposed micropump structure with previous work.

\begin{tabular}{cccccccc}
\hline References & Structure type & Chip size & $\begin{array}{c}\text { Applied } \\
\text { voltage }\end{array}$ & $\begin{array}{c}\text { Pumping } \\
\text { force }\end{array}$ & Flow rate & $\begin{array}{c}\text { Status of structure } \\
\text { for fabrication }\end{array}$ & $\begin{array}{c}\text { Flow rate } \\
\text { Controllability }\end{array}$ \\
\hline Karajgikar [16] & $\begin{array}{c}\text { SOI } \\
\text { Electrostatic }\end{array}$ & Not mentioned & $14-24 \mathrm{~V}$ & $3.73 \mathrm{mN}$ & $11.2 \mu \mathrm{L} / \mathrm{min}$ & simple & No \\
Teymoori [6] & $\begin{array}{c}\text { (two substrate) } \\
\text { (twik }\end{array}$ & $4 \times 7 \times 1 \mathrm{~mm}^{3}$ & $18 \mathrm{~V}$ & Not mentioned & $9.1 \mu \mathrm{L} / \mathrm{min}$ & complex & No \\
Chandika [27] & Piezoelectric & $\sim 48 \times 8 \times 0.39 \mathrm{~mm}^{3}$ & $100 \mathrm{~V}$ & - & $7.1 \mathrm{~mL} / \mathrm{min}$ & complex & No \\
Kim [22] & Tube-type & $5 \times 5 \times 10 \mathrm{~mm}^{3}$ & $2000 \mathrm{~V}$ & - & $0.05 \mathrm{~cm}^{3} / \mathrm{s} \mathrm{or}$ & complex & Yes \\
Proposed [28] & SOI & $2 \times 2.3 \times 0.1 \mathrm{~mm}^{3}$ & $8 \mathrm{~V}$ & $4.4 \mathrm{mN}$ & $16 \mu \mathrm{L} / \mathrm{min}$ & simple & Yes \\
\hline
\end{tabular}

\section{Acknowledgments}

The authors would like to thank all people involved in this research work for their kind and responsible assistance. Special thanks are given to Prof. Ghader Rezazadeh, Dr. Hadi Tawakkoli and Dr. Ako Parsa for their helpful assistance.

\section{Author Contributions}

Ghader Yosefi designed concept and organized the study and then did analyzing and simulations. Sattar Mirzakuchaki suggested proportional subject and suitable references. He also edited the study 
specially and technically. Farshid Raissi suggested the special Martials in the structure to have best operation and introducing high pumping force. Saeid Afrang prepared the Intellisuite tools and trained the first author. He also suggested and edited fabrication instructions specially.

\section{Conflicts of Interest}

The authors declare no conflict of interest.

\section{References}

1. Nisar, A.; Afzulpurkar, N.; Mahaisavariya, B.; Tuantranont, A. MEMS-based micropumps in drug delivery and biomedical applications. Sens. Actuators B Chem. 2008, 130, 917-942.

2. Kan, J.; Yang, Z.; Peng, T.; Cheng, G.; Wu, B. Design and test of a high-performance piezoelectric micropump for drug delivery. Sens. Actuators A Phys. 2005, 121, 156-161.

3. Tsai, N.C.; Sue, C.Y. Review of MEMS-based drug delivery and dosing systems. Sens. Actuators A Phys. 2007, 134, 555-564.

4. Ashraf, M.W.; Tayyaba, S.; Afzulpurkar, N. Micro electromechanical systems (MEMS) based microfluidic devices for biomedical applications. Int. J. Mol. Sci. 2011, 12, 3648-3704.

5. Wei, W.; Guo, S. A Novel PDMS Diaphragm Micropump Based on ICPF Actuator. In Proceedings of IEEE International Conference on Robotics and Biomimetics, Tianjin, China, 14-18 December 2010; pp. $1577-1583$.

6. Teymoori, M.M.; Abbaspour-Sani, E. Design and simulation of a novel electrostatic peristaltic micromachined pump for drug delivery applications. Sens. Actuators A Phys. 2005, 117, 222-229.

7. Sin, J.; Lee, W.H.; Stephanou, H. In-plane micropump: Design optimization. In Proceedings of the 2004 NSTI Nanotechnology conference and Trade show, Boston, MA, USA, 7-11 March 2004; pp. 271-274.

8. Ji, Q.; Scott, K.L. First Order Modeling of Thermal Actuators in SUGAR; Department of Electrical Engineering and Computer Sciences, University of California: Berkeley, CA, USA, 2003.

9. Mhatre, A.A. Implantable Drug Delivery System with an In-Plane Micropump. Master's Thesis, University of Texas, Arlington, TX, USA, May 2006.

10. Standard Test Method for Measuring Resistivity of Silicon Wafers with an In-Line-Four-Point Probe; ASTM International: West Conshohocken, PA, USA, 1999.

11. Prakash, C. Thermal conductivity variation of silicon with temperature. Microelectron. Reliab. 1978, 18, 333.

12. Siegert, L.; Capelle, M.; Roqueta, F.; Lysenko, V.; Gautier, G. Evaluation of mesoporous silicon thermal conductivity by electrothermal finite element simulation. Nanoscale Res. Lett. 2012, 7, 1-7.

13. Geisberger, A.A.; Sarkar, N.; Ellis, M.; Skidmore, G.D. Electrothermal properties and modeling of polysilicon microthermal actuators. IEEE J. Microelectromech. Syst. 2003, 12, 513-523.

14. Kole, A.; Jeongsik, S.; Lee, W.H.; Popa, D.; Agonafer, D.; Stephanou, H. Polymer tube embedded in-plane micropump for low flow rate. In Proceedings of IEEE the 24th Digital Avionics Systems Conference, Washington, DC, USA, 30 October-3 November 2005. 
15. Kole, A.; Sin, J.; Lee, W.H.; Popa, D.; Agonafer, D.; Stephanou, H. Design of polymer tube embedded in-plane micropump. In Proceedings of the Tenth Intersociety Conference on Thermal and Thermomechanical Phenomena in Electronics Systems, San Diego, CA, USA, 30 May-2 June 2006; pp. 1324-1329.

16. Karajgikar, S.; Rao, S.; Sin, J.; Agonafer, D.; Chiao, J.C.; Popa, D.; Stephanou, H. Electro-thermal analysis of in-plane micropump. IEEE Trans. Compon. Packag. Thecnol. 2010, 33, 329-339.

17. Lai, Y.; Mc Donald, J.; Kujath, M.; Hubbard, T. Force, deflection and power measurements of toggled microthermal actuators. J. Micromech. Microeng. 2004, 14, 49-56.

18. Guo, C.; Tatar, E.; Fedder, G.K. Large-Displacement Parametric Resonance Using a Shaped Comb Drive. In Proceedings of IEEE 26th International Conference on Micro Electro Mechanical Systems, Taipei, Taiwan, 20-24 January 2013; pp. 173-176.

19. Gerson, Y.; Krylov, S.; Ilic, B.; Schreiber, D. Design considerations of a large-displacement multistable micro actuator with serially connected bistable elements. Finite Elem. Anal. Des. 2012, 49, 58-69.

20. Cheng, C.H.; Tseng, Y.P. Characteristic studies of the piezoelectrically actuated micropump with check valve. Microsyst. Technol. 2013, 19, 1707-1715.

21. Rao, S.M.N.; Mhatre, A.; Popa, D.; Chiao, J.-C.; Ativanichayaphong, T.; Sin, J.; Stephanou, H. MEMS based implantable drug delivery system. In Proceedings of VII International Conference on Micro Electro Mechanical Systems, El Paso, TX, USA, 21-22 September 2005.

22. Kim, J.; Nguyen, T.V.X.; Yokota, S.; Edamura, K. MEMS-based tube-type micropump by using electro-conjugated fluid (ECF). In Proceedings of IEEE XIX International Conference on Electrical Machines, Rome, Italy, 6-8 September 2010; pp. 1-5.

23. Noh, H.S.; Huang, Y.; Hesketh, P.J. Parylene micromolding, a rapid and low-cost fabrication method for parylene microchannel. Sens. Actuators B Chem. 2004, 102, 78-85.

24. Sinclair, M.J. A High Force Low Area MEMS Thermal Actuator. In Proceedings of IEEE the Seventh Intersociety Conference on Thermal and Thermomechanical Phenomena in Electronic Systems, Las Vegas, NV, USA, 23-26 May 2000; pp. 127-132.

25. Huang, Q.A.; Lee, N.K.S. Analysis and design of polysilicon thermal flexure actuator. J. Micromech. Microeng. 1999, 9, 64-70.

26. Varona, J.; Tecpoyotl-Torres, M.; Hamoui, A.A. Modeling of MEMS Thermal Actuation with External Heat Source. In Proceedings of IEEE Electronics, Robotics and Automotive Mechanics Conference, Morelos, Mexico, 25-28 September 2007; pp. 591-596.

27. Chandika, S.; Asokan, R.; Vijayakumar, K.C.K. Flow characteristics of the diffuser/nozzle micropump-A state space approach. Flow Meas. Instrum. 2012, 28, 28-34.

28. Yosefi, G. Design a Novel Structure of Bio MEMS Micro Sensor and Micro Pump for Diagnosis Blood Glucose Level and Suitable Insulin Injection. Ph.D. Thesis, Islamic Azad University, Tehran, Iran, 1 September 2013.

(C) 2014 by the authors; licensee MDPI, Basel, Switzerland. This article is an open access article distributed under the terms and conditions of the Creative Commons Attribution license (http://creativecommons.org/licenses/by/4.0/). 